\title{
A Case of Iron Intoxication Treated by Plasmapheresis
}

\author{
Nagehan Aslan ${ }^{1}$ (1) \\ Received: 4 October 2021 / Accepted: 11 November 2021 / Published online: 26 November 2021 \\ (c) Dr. K C Chaudhuri Foundation 2021
}

To the Editor: The clinical use of plasmapheresis can include intoxications [1]. The effective plasmapheresis procedure in a pediatric patient with severe iron intoxication will be discussed here.

A 21-mo-old girl was brought to the emergency department after it was discovered that she had taken $360 \mathrm{mg}$ elemental iron/kg which belonged to her mother. The patient, who had a serum iron level of $548 \mathrm{mcg} / \mathrm{dL}$, had gastric lavage in the emergency room and was admitted to the pediatric intensive care unit. The patient was lethargic and had vomiting and diarrhea. Laboratory tests revealed severe metabolic acidosis. The patient received desferrioxamineas chelation treatment intravenously. The abdominal radiograph revealed an opacity of iron tablets. Whole bowel irrigation with polyethylene glycol was planned. Due to difficulties in the effective oral application of polyethyleneglycol, such as the patient's age, disobedience of commands, and being lethargic, a nasogastric tube was implanted to help the patient to receive polyethyleneglycol enterally. Sedation infusion was started due to patient noncompliance to nasogastric tube. Polyethyleneglycol $500 \mathrm{~mL} / \mathrm{h}$ was applied. After $3 \mathrm{~h}$, the serum iron level increased to $850 \mathrm{mcg} / \mathrm{dL}$, and plasmapheresis was performed. The iron level measured at the 6th hour after the procedure was $80 \mathrm{mcg} / \mathrm{dL}$. The patient's gastrointestinal symptoms improved rapidly after procedure and oral feeding was started. She was transferred to the ward at the 36th hour of her intensive care hospitalization.

Plasmapheresis is effective in removing highly protein bound drugs with a low volume of distribution, but there are no controlled studies on the effectiveness of plasmapheresis in any specific intoxication [2]. There is no reported case of iron intoxication treated with plasmapheresis in the pediatric literature, despite the fact that there are some cases of iron intoxication treated with exchange transfusion [3, 4]. Plasmapheresis was performed as an alternative therapy, and a dramatic decrease of serum iron level was detected in our case.

\section{Declarations}

Conflict of Interest None.

\section{References}

1. Ibrahim RB, Liu C, Cronin SM, et al. Drug removal by plasmapheresis: an evidence-based review. Pharmacotherapy. 2007;27:1529-49.

2. Nenov VD, Marinov P, Sabeva J, Nenov DS. Current applications of plasmapheresis in clinical toxicology. Nephrol Dial Transplant. 2003;18:v56-8.

3. Tomlinson B. Ferrous sulphate poisoning treated by exchange transfusion. Lancet. 1964;2:1015.

4. Amerman EE, Brescia MA, Aftahi F. Ferrous sulphate poisoning; report of a case successfully treated by exchange transfusion. $\mathbf{J}$ Pediatr. 1958;53:476-8.

Publisher's Note Springer Nature remains neutral with regard to jurisdictional claims in published maps and institutional affiliations.

Nagehan Aslan

nagehan_aslan@hotmail.com

1 Department of Pediatric Intensive Care, Malatya Training and Research Hospital, Malatya 44000, Turkey 